Khudhair Abed Thamer

Al-Maaref University College, Republic of Iraq

\title{
RELATIONS AND OPERATIONS ON PREDICATES IN THE THEORY OF INTELLIGENCE
}

\begin{abstract}
Purpose. The purpose of the paper is to develop a formal technique of the theory of intelligence, namely, to develop the model and axiomatics in the language of algebra of finite predicates (AFP); to introduce a system of operations on relations; to construct of the algebra of relations. Methods. The methods of algebra of finite predicates, Boolean algebra and axiomatic method are used in the paper. Results. In the paper the mathematical apparatus of the theory of intellect was further developed. The models and axiomatics of relations in the language of algebra of finite predicates (AFP) are developed, operations on relations such as the injection, equivalence, surjection, quasi-order, partial order, circulation and product of the relation are introduced. The algebra of relations is constructed. The system of operations on predicates in the algebra of finite predicates, namely, the Boolean negation, disjunction, conjunction, implication, equivalence is axiomatically assigned. The basic predicates (predicates of object recognition) are introduced. Conclusions. The predicates of different orders correspond to concepts of a different level of abstraction. The solution of the AFP equations can be interpreted as a creative activity of a person. Due to the presence of such a wide and meaningful interpretation, even the purely mathematical development of the AFP allows at the same time to impel the development of the theory of intelligence. The minimization, decomposition, solution of equations, identical transformation of formulas are important tasks of the theory of intelligence.
\end{abstract}

Keywords: theory of intelligence; algebra of finite predicates; comparator identification.

\section{Introduction}

The present paper is a continuation of the paper [1], in which a multidimensional predicate model of comparator identification $[2,3]$ was proposed and the axiomatics of this model was substantiated.

In the article were obtained mathematical results aimed at developing the formal apparatus of the theory of intelligence [4-12].

Models and axiomatics of relations in the language of algebra of finite predicates (AFP) and the operations on predicates are considered.

\section{Relations}

Any ordered collection of any elements $a_{1}, a_{2}, \ldots, a_{n}$ is called a set, a list, or a sequence. Elements that form a set are called its components. Each component in the set is characterized by its place, so that changing the places of different elements in the set leads to a change in the entire set. Sets may differ from each other in the number of components $n$, as well as the composition or order of the elements in the set. To record a set, is used a list of all its components, enclosed in parentheses: $\left(a_{1}, a_{2}, \ldots, a_{n}\right)$. The sets will be denoted by lowercase Latin letters, for example, $a=\left(a_{1}, a_{2}, \ldots, a_{n}\right)$.

The parts of the components in the set are numbered from left to right. At different places in the set there can be both different and identical elements. Onecomponent set is called - unary, bicomponent - binary, three-component - ternary, $n$-component $-n$-ary. The number of components in a set is called its arity. A binary set is called an ordered pair or simply a pair. Any unary set $(a)$ coincides with the element $a$. If the characters $a$ and $b$ denote the same set, then it is said that the sets $a$ and $b$ are equal and it is written $a=b$. Two sets $a=\left(a_{1}, a_{2}, \ldots, a_{m}\right), \quad b=\left(b_{1}, b_{2}, \ldots, b_{n}\right) \quad$ are equal only if $m=n$ and $a_{i}=b_{i}$ for all $\mathrm{n} i=\overline{1, m}$. The sets can be built not only from the elements, but also from the sets according to the rule

$$
\begin{gathered}
\left(\left(a_{1}, a_{2}, \ldots, a_{m}\right),\left(b_{1}, b_{2}, \ldots, b_{n}\right)\right)= \\
=\left(a_{1}, a_{2}, \ldots, a_{m}, b_{1}, b_{2}, \ldots, b_{n}\right) .
\end{gathered}
$$

Let's assume that $A_{1}, A_{2}, \ldots, A_{n}$ - nonempty subsets of the universe $U$. Let's make a set $a=\left(a_{1}, a_{2}, \ldots, a_{n}\right)$ of the elements $a_{1} \in A_{1}, a_{2} \in A_{2}, \ldots, a_{n} \in A_{n}$. The set $A=A_{1} \times A_{2} \times \ldots \times A_{n}$ all such sets is called the Cartesian product of sets $A_{1}, A_{2}, \ldots, A_{n}$. We can talk about belonging of $a \in A$ set $a$ to the Cartesian product $A$. If $n=2$ and $A_{1}=A_{2}=A$, then the Cartesian product is called the Cartesian square or simply the square of the set $A: A \times A=A^{2}$. The Cartesian product $A \times A \times A=A^{3}$ is called the cube of set $A$. The Cartesian product $A \times A \times \ldots \times A$, where $A$ is met $n$ one time, is called $n$-stage of the set $A$ and is written as $A^{n}$.

The operation $\times$ of obtaining a Cartesian product $A \times B$ from the set $A$ and $B$ is associative:

$$
(A \times B) \times C=A \times(B \times C)
$$

at any $A, B, C$. In combination with operations $\cup$, $\cap$, The operation of the Cartesian product of sets has the following properties:

$$
\begin{gathered}
(A \cap B) \times(C \cap D)=(A \times C) \cap(B \times D), \\
(A \cup B) \times C=(A \times C) \cup(B \times C) \\
(A \times(B \cup C)=(A \times B) \cup(A \times C) \\
(A \cup B) \times(C \cup D)= \\
=(A \times C) \cup(B \times C) \cup(A \times D) \cup(B \times D)
\end{gathered}
$$


for any $A, B, C, D$. The relations $\in$, = and $\subseteq$ In combination with operations $\times, \cup, \cap,{ }^{-}$possess the following properties: $\left(a_{1}, a_{2}, \ldots, a_{n}\right) \in A_{1} \times A_{2} \times \ldots \times A_{n}$ is equally matched to $a_{1} \in A_{1}, a_{2} \in A_{2}, \ldots, a_{n} \in A_{n}$ for any $a_{1}, a_{2}, \ldots, a_{n}$ and $A_{1} \times A_{2} \times \ldots \times A_{n} ; A \subseteq B$ and $C \subseteq D$ is equally matched to $A \times C \subseteq B \times D ; A=B$ and $C=D$ is equally matched to $A \times C \subseteq B \times D$; $(A \times B) \cup(C \times D) \subseteq(A \cup C) \times(B \cup D) ; \quad A \subseteq C$ and $B \subseteq D \quad$ results in $A \times B=(A \times D) \cap(C \times B)$; $(A \times B) \cup(B \times A)=C \times D$ results in $A=B=C=D$ for any $A, B, C, D$.

Any subset $P$ of the Cartesian product $A$ of the sets $A_{1}, A_{2}, \ldots, A_{n}$ is called the relation, defined for $A=A_{1} \times A_{2} \times \ldots \times A_{n}$. the relation $\varnothing$, not containing a single set, is called empty; the relation $P$, consisting of all the sets of the Cartesian product $A$, is called complete. The relations, as well as sets, we will denote in bold capital Latin letters. At $n=1$ the relation is called unary, at $n=2$ - binary, at $n=3$ - ternary. At arbitrary value $n$ the relation is called $n$-ary. About $n$ ary relation, defined for $A^{n}$, or brevity, it is said that it is defined for $A$. Instead of expression «the relation $P$, defined for $A$ » is briefly called «the relation $P$ for $A \gg$. For tasks in which the Relations appear for $A$, the set $A$ plays the role of the universe, and the relations themselves are the role of subsets of this universe.

We can speak of the attribute of a set to the relation, equality and inclusion of relations on $A$, as well as on their integration, intersection and addition. Thus, on the set of all relations is defined an algebra, which is a kind of Boolean algebra. The unification of the relations is called their disjunction, the intersection the conjunction, the complement - the negation of the relations. We can talk about the Cartesian product $P \times Q$ of the relations $P$ and $Q$. The predicating $\left(a_{1}, a_{2}, \ldots, a_{m}\right) \in P \quad$ and $\quad\left(b_{1}, b_{2}, \ldots, b_{m}\right) \in Q \quad$ equally match the predication

$$
\begin{gathered}
a_{1} \in A_{1}, a_{2} \in A_{2}, \ldots, a_{m} \in A_{m}, \\
b_{1} \in B_{1}, b_{2} \in B_{2}, \ldots, b_{n} \in B_{n}, P \subseteq A, Q \subseteq B,
\end{gathered}
$$$$
\left(a_{1}, a_{2}, \ldots, a_{m}, b_{1}, b_{2}, \ldots, b_{m}\right) \in P \times Q
$$

where $A=A_{1} \times A_{2} \times \ldots \times A_{m}$ and $B=B_{1} \times B_{2} \times \ldots \times B_{n}$.

If the set belongs to the relation $P$, then it is called a vector of the relations $P$. For binary relations, except for the record $(a, b) \in P$, is used a record equivalent to it $a P b$. If $(a, b) \notin P$, then it is written $a \bar{P} b$. The binary relation $D$, composed of all pairs of the form $(a, a)$, where $a \in U$, is called equality or diagonal, the relation, defined for the universe $U$. To define the relations $D$ is also used the character $=$. The pairs in the form of $(a, a)$ are called diagonal. The relation of equality is reflexive: $a=a$ for any $a$; symmetrically: $a=b$ results in $b=a$ for any $a, b$; transitively: $a=b$ and $b=c$ results in $a=c$ for any $a, b, c$. The relation of equality can be defined not only on the universe $U$, but also on any of its subsets $A$. In this case one speaks of equality on $A$.

The relation $F$, defined for $A \times B$, is called functional if it satisfies the single-valued condition: for any $a \in A$ and $b, c \in B \quad a F b$ and $a F c$ results in $b=c$. It is said that the functional relation $F$, defined for $A \times B$, determines the corresponding function or operation $f$, acting from the set $A$ to the set $B$. The functions will be denoted by lowercase Latin or Greek letters. If for $a \in A$ is found an element $b \in B$ is such, that $a F b$, then the function $f$ aligns the element $a$ the only element $b$. This fact is written as follows: $b=f(a)$ if $b=f a$. If for $a \in A$ there is not $b \in B$ such an element, that $a F b$, then the function $f$ does not associate an element with $a$ any element from the set $B$. In this case it is said that the function $f$ for the element $a \in A$ is not defined.

The function $f$ can be determined by indicating the corresponding relation $F$. In order for the definition of a function to be logically flawless (correct), it must be proved that the relation $F$ obeys the uniqueness condition. Such a proof is called a verification of the correctness of the definition of a function $f$. The relation of equality $D$ for $A$ defines the function $d$, is called the identity. It is characterized by the property: $a=d(a)$ for every $a \in A$.

If $b=f(a)$, then the element $b \in B$ is called the image of element $a \in A$, and the element $a$-preimage of element $b$ in relation to the function $f$. The collection of all inverse images of an element $b$ in relation to the function $f$, contained in the set $A$, is called a complete preimage of element $b$ in $A$ in relation to the function $f$. The set $A$ is called scope of dispatch of function $f$, The set $B-$ e arrival area. The set of all elements $a \in A$, for each of which there is an element $b \in B$, fulfilling the condition $b=f(a)$, is called an area of definition of a function $f$. The set of all the elements $b \in B$ for each of which there is an element $a \in A$, fulfilling the condition $b=f(a)$, is called the range $f$. If the area of the dispatch of function $f$ is a Cartesian product $A=A_{1} \times A_{2} \times \ldots \times A_{n}$, then it is said that the function $f n$-place.

A function is called everywhere defined if its domain of definition coincides with the domain of departure, otherwise it is called partial. It is said that an everywhere defined function $f$ defined for $A \times B$, reflects the set $A$ to the set $B$, and it is written $f: A \rightarrow B$. Sometimes, for brevity, an everywheredefined function is simply called a function. Everywhere a certain function is called surjection, if its range of values coincides with the arrival area. It is said, that a surjection, defined for $A \times B$, reflects the set $A$ for the set $B$. It is said that surjection $f: A \rightarrow A$ reflects the set $A$ for itself. 
Everywhere defined function $f$, defined for $A \times B$ is called an injection, if for each $b \in B$ there is no more than one element $a \in A$, satisfying the condition $b=f(a)$. The surjective and injective function is called the bijection. It is said that that a bijective function on $A \times B$ one-to-one reflects the set $A$ for the set $B$. The final areas of departure and arrival of the bijection consist of the same number of elements, and the infinite ones are equinumerous.

The binary relation $E$ for $A$ is called the equivalence if it is reflexive: $a E a$ for any $a \in A$; symmetrically: $a E b$ results in $b E a$ for any $a, b \in A$; transitively: $a E b$ and $b E c$ results in $a E c$ for any $a, b, c \in A$. The relation of equality $D$ is an equivalence. Partitioning $S$ of the set $A$ is called any system of nonempty subsets of the set $A$, such that each element of the set $A$ belongs to only one of them. Of the set $S$, are called layers or adjacent partition classes $S$.

To each equivalence $E$ for $A$ one can put in oneto-one correspondence the decomposition $S$ of the set $A$, and vice versa, according to the following rule: if $a E b$, then $a$ and $b$ are put in one layer of the partition $S$, if $a \bar{E} b$, then to the different. So related equivalence $E$ and the partitioning $S$ are called corresponding to each other. The equality $D$ for $A$ corresponds to a partition of the set $A$, is made up of singleton layers.

The partition $S$, corresponding to the equivalence $E$ for $A$, is called the factor - the set from $A$ to $E$ and defined $A \backslash E$. The surjection $f_{E}: A \rightarrow A \backslash E$, which to each element $a \in A$ puts in correspondence its containing layer of decomposition $S$, is called the canonical image $A$ for $A \backslash E$. The canonical image $f_{E}: A \rightarrow A \backslash E$ will be a bijection if and only if the equivalence $E$ coincides with the equality $D$.

Let $f$ - the surjection representing $A$ for $B$. Let's define for $A$ the equivalence $E$, considering that $a E b$ only if $f(a)=f(b)$. The layers $S$, corresponding to the equivalece $E$, are complete preimages in $A$ items from the set $B$. By matching each element of the set $B$ its complete preimage in $A$, are obtained a bijection that maps $B$ for $A \backslash E$. This bijection is called the canonical image $B$ for $A \backslash E$. the equivalence $E$ is called the nuclear for function $f$.

The binary relation of the sets $A$ is called quasiorder if it is reflexive and transitively. The partial order is quasi-order $P$, fulfilling the condition of antisymmetry: $a P b$ and $b P a$ results in $a=b$ for every $a, b \in A$. For a partial order is used a special notation $\leq$. if $a \leq b$ and $a \neq b$, then it is written $a<b$ and say that $a$ is less $b$. The record $a \leq b$ means that $a$ is less or equal to $b$. The element $a \in A$ is called the largest in $A$ with respect to partial order $\leq$ for $A$, if $b \leq a$ for every $b \in A$; the least - if $a \leq b$. The elements $a$ and $b$ of the set $A$ are named to be comparable with respect to the partial order $\leq$ for $A$, if $a \leq b$ or $b \leq a$.
Partial order $\leq$ for $A$ is called the linear order on $A$, if any $a, b \in A$ are relatively compared $\leq$. The set, on which a partial order is specified, is called partially ordered; linear - linearly ordered or chain.

The binary relation $Q$ for $B \times A$ is called an inverse to the relation $P$ for $A \times B$, if it satisfies condition: $a P b$ is equally matched to $b Q a$ for every $a \in A$ and $b \in B$. The operation ${ }^{*}$ which corresponds to each relation $P$ for $A \times B$ the relation opposite to it $P^{*}$ for $B \times A$, is called the converse the relations $P$. The factum of the relations $P$ for $A \times B$ and $Q$ for $B \times A$ is called the relation $R$ for $A \times C$, satisfying the condition: for any $a \in A$ and $c \in C$ the predicating «exists $b \in B$, such that $a P b$ and $b Q c$ » equally match the predication $a R c$. The operation $\circ$, which puts in correspondence the relations $P$ for $A \times B$ and $Q$ for $B \times C$ their factum $P \circ Q$ for $A \times C$, is called the multiplication of the relations. The factum $H=F \circ G$ of functional relations $F$ and $G$ and corresponds to the function $h=g f$, is called the superposition of functions $f$ and $g$, of the corresponding relations $F$ and $G$. If $x F \circ G y$, then it is written $y=g((f(x))=g f(x)$.

Algebra of the relations for $A$ is called the set of all binary of the relations on $A$ with the operations defined on it $\cup, \cap,{ }^{-}$, $\circ$ and ${ }^{*}$. In the algebra of the relations, all the basic identities of Boolean algebra are valid. The role of operations $=$, · and ' in the algebra of the relations, they perform the operations of union, intersection and addition of the relations. Operations $\circ$ and ${ }^{*}$ obey the following identities:

$$
\begin{gathered}
\left(P^{*}\right)^{*}=P, \\
(P \circ Q) \circ R=P \circ(Q \circ R), \\
(P \circ Q)^{*}=P^{*} \circ Q^{*}, \\
\overline{P^{*}}=(\bar{P})^{*}, \\
(P \cup Q)^{*}=P^{*} \cup Q^{*}, \\
(P \cap Q)^{*}=P^{*} \cap Q^{*}, \\
P \circ(Q \cup R)=(P \circ Q) \cup(P \circ R), \\
(P \cup Q) \circ R=(P \circ R) \cup(Q \circ R),
\end{gathered}
$$

Which, together with the basic identities of the Boolean algebra, are considered the basic identities in the algebra of the relations. The analogue of the last two identities for the operation $\cap$ is incorrect, instead of them there are inclusions

$$
\begin{aligned}
& P \circ(Q \cap R) \subseteq(P \circ Q) \cap(P \circ R), \\
& (P \cap Q) \circ R \subseteq(P \circ R) \cap(Q \circ R) .
\end{aligned}
$$

The character $P, Q$ and $R$ denote arbitrary binary relations on $A$. 


\section{Predicates}

Let's consider a formal language, the algebra of finite predicates, with the help of which predicates realized by the subject can be mathematically expressed [1]. First, let's consider the algebra of logic, which is used to use the introduction of the algebra of predicates. Let's introduce the set $\Sigma=\{0,1\}$. The symbols 0 and 1 are called Boolean elements. The symbol 0 is called zero or false, the symbol 1 is one or true. Variable, defined for set $\Sigma$, is called Boolean. Boolean variables will be denoted by lower case letters of the Greek alphabet.

The single operation $\beta=\bar{\alpha}$, displaying the set $\Sigma$ itself and defined by the equalities

$$
\overline{0}=1
$$

and

$$
\overline{1}=0,
$$

is called Boolean negation.

Double operation $\gamma=\alpha \vee \beta$, reflecting $\Sigma^{2}$ for $\Sigma$ and defined by the equalities

$$
\begin{aligned}
& 0 \vee 0=0, \\
& 0 \vee 1=1, \\
& 1 \vee 0=1, \\
& 1 \vee 1=1,
\end{aligned}
$$

is called a Boolean disjunction or Boolean addition. Double operation $\gamma=\alpha \wedge \beta=\alpha \cdot \beta=\alpha \beta$, reflecting $\Sigma^{2}$ for $\Sigma$ and defined by the equalities

$$
\begin{aligned}
& 0 \wedge 0=0, \\
& 0 \wedge 1=0, \\
& 1 \wedge 0=0, \\
& 1 \wedge 1=1,
\end{aligned}
$$

is called a Boolean conjunct or Boolean multiplication.

The set $\Sigma$, together with the operations defined on it ${ }^{-}, \vee$ and $\wedge$, is called algebra of logic. The algebra of logic is a kind of Boolean algebra. The role of operations,$+ \cdot$ and ' in algebra, the logic performs operations $\vee, \wedge$ and ${ }^{-}$. In the algebra of logic all the basic identities of Boolean algebra are valid. Functions obtained by superposition of operations ${ }^{-}, \vee$ and $\wedge$, are called Boolean functions. Boolean function

$$
\alpha \supset \beta=\alpha \vee \bar{\beta}
$$

is called the implication, the Boolean function

$$
\alpha \sim \beta=(\alpha \supset \beta) \wedge(\alpha \supset \beta)-
$$

the equivalence.

The predicate $P$, defined for $U^{n}$, is called any function $\zeta=P\left(x_{1}, x_{2}, \ldots, x_{n}\right)$, reflecting the set $\Sigma^{n}$ to the set $\Sigma$. The variables $x_{1}, x_{2}, \ldots, x_{n}$ are called subject, and their meanings are objects. If $n=1$, the predicate $P$ is called unary, if $n=2$ - binary, if $n=3-$ ternary. At an arbitrary value $n$ the predicate is called $n$-ary. if the set $U$ is the final, the predicate $P$ is called finite, otherwise - infinite.

A predicate equal to one for every set of values of its arguments, is called identically true; equal to zero identically false. and 0 .

These predicates are denoted by the symbols 1

Disjunction or logical addition of predicates $P$ and $Q$ is called the predicate $P \vee Q$, values of which at any $x_{1}, x_{2}, \ldots, x_{n} \in U$ are determined by the formula

$$
\begin{gathered}
(P \vee Q)\left(x_{1}, x_{2}, \ldots, x_{n}\right)= \\
=P\left(x_{1}, x_{2}, \ldots, x_{n}\right) \vee Q\left(x_{1}, x_{2}, \ldots, x_{n}\right) .
\end{gathered}
$$

The conjunction or logical addition of predicates $P$ and $Q$ is called the predicate $P \wedge Q=P \cdot Q=P Q$ with the values

$$
\begin{gathered}
(P \wedge Q)\left(x_{1}, x_{2}, \ldots, x_{n}\right)= \\
=P\left(x_{1}, x_{2}, \ldots, x_{n}\right) \wedge Q\left(x_{1}, x_{2}, \ldots, x_{n}\right) .
\end{gathered}
$$

The negation of the predicate $P$ is called the predicate $\bar{P}$ with the values

$$
(\bar{P})\left(x_{1}, x_{2}, \ldots, x_{n}\right)=P\left(x_{1}, x_{2}, \ldots, x_{n}\right) .
$$

On the right-hand side of (29) - (31), the signs $\vee$, $\wedge,{ }^{-}$is denoted the Boolean disjunction, conjunction and negation. On the left-hand side of the same equations, the signs $\vee, \wedge, \quad$ are denoted operations of disjunction, conjunction and negation of predicates.

The set of all $n$-ary predicates, assigned for $U^{n}$, on which the operations of disjunction, conjunction and negation are defined, predicates is called algebra $n$-ary predicates for $U$.

The operations of disjunction, conjunction and negation of predicates are called basic for the algebra of predicates.

The algebra of predicates at any value $n$ is a kind of Boolean algebra. In it all the basic identities of Boolean algebra are satisfied.

In the algebra of predicates, the role of the elements 0,1 and operations + , ' and ' perform respectively the identically false and identically true predicates and operations of disjunction, conjunctions and negations of predicates.

Predicates of the form:

$$
x_{i}^{a}=\left\{\begin{array}{l}
1, \text { если } x_{i}=a, \\
0, \text { если } x_{i} \neq a
\end{array}\right.
$$

are called basic for the algebra of predicates. Here $i=\overline{1, n}, a-$ any element of the universe $U$. If the universe is finite and consists of $k$ the elements, then everything is available $k n$ of the different basic elements.

The algebra of predicates is complete in the sense that any of its predicates can be represented in the form 
of a certain superposition of basic operations that are changed to basic elements.

The predicate $x_{i}^{a}$ is called the recognition of an object $a$ under the variable $x_{i}$.

For item recognition at any $i=\overline{1, n}$ the following identities are valid:

Law of truth

$$
\underset{a \in U}{\vee} x_{i}^{a}=1,
$$

law of negation - for any $a \in U$

$$
\overline{x_{i}^{a}}=\underset{\substack{b \in U \\ b \neq a}}{\vee} x_{i}^{b}
$$

law of falsity - for any $a, b \in U$, if $a \neq b$, then

$$
x_{i}^{a} x_{i}^{b}=0 .
$$

The record $\underset{a \in U}{\vee}$ means the logical sum of the operation that is executed for every $a$, belonging to the universe $U$.

If universe is final $U=\left\{x_{1}, x_{2}, \ldots, x_{k}\right\}$, then the newly derived identities can be rewritten in the form: of the truth law $i=\overline{1, n}$

$$
x_{i}^{a_{1}} \vee x_{i}^{a_{2}} \vee \ldots \vee x_{i}^{a_{k}}=1 \text {, }
$$

law of negation - for any $i=\overline{1, n}$ and $j=\overline{1, k}$

$$
\overline{x_{i}^{a_{j}}}=x_{i}^{a_{1}} \vee x_{i}^{a_{2}} \vee \ldots \vee x_{i}^{a_{j-1}} \vee x_{i}^{a_{j+1}} \vee \ldots \vee x_{i}^{a_{k}} \text {, }
$$

law of falsity - for any $i=\overline{1, n}, j=\overline{1, k}$ and $j \neq 1$

$$
x_{i}^{a_{j}} x_{i}^{a_{1}}=0 .
$$

Let $P-$ the relation, defined for $U^{n}$. The predicate $P$, values of which are calculated by the rule

$$
\begin{gathered}
P\left(x_{1}, x_{2}, \ldots, x_{n}\right)= \\
=\left\{\begin{array}{l}
1, \text { если }\left(x_{1}, x_{2}, \ldots, x_{n}\right) \in P, \\
0, \text { если }\left(x_{1}, x_{2}, \ldots, x_{n}\right) \notin P,
\end{array}\right.
\end{gathered}
$$

is called the predicate, relevant to the relation $P$. To each relation $P$ for $U^{n}$ corresponds its own predicate $P$ for $U^{n}$ and vice versus. The presence of such a oneto-one correspondence between the relations and the predicate makes it possible to write mathematically any of the relations in the form of some formula of the predicate algebra over which the values of the predicate corresponding to this relation can be calculated.

For example, to the relation

$$
P=\{(n, a, n, a), \quad(\mathcal{M}, a, \mathcal{M}, a)\}
$$

corresponds the predicate $P$, values of which are determined by the formula

$$
P\left(x_{1}, x_{2}, x_{3}, x_{4}\right)=x_{2}^{a} x_{4}^{a}\left(x_{1}^{n} x_{3}^{n} \vee x_{1}^{M} x_{3}^{M}\right) .
$$

The variables $x_{1}, x_{2}, x_{3}, x_{4}$, the figures appearing in the formula can be interpreted meaningfully as the names of the first, second, third and fourth places of the elements in the sets forming the relation $P$ (counting from the left is wrong).

The recording $x_{1}=n, x_{2}=a, x_{3}=n, x_{4}=a$ means that in this case it is a matter of typing $(n, a, n, a)$, on the first and third places of which there is a letter $n$, and on the second and fourth - the letter $a$.

Any predicate $P$, preset at $U^{n}$, can be expressed by the following formula of the algebra of predicate

$$
\begin{gathered}
P\left(x_{1}, x_{2}, \ldots, x_{n}\right)= \\
=\underset{\left(a_{1}, a_{2}, \ldots, a_{n}\right) \in P}{\vee} x_{i}^{a_{1}} \vee x_{i}^{a_{2}} \vee \ldots \vee x_{i}^{a_{n}},
\end{gathered}
$$

is called the perfect disjunctive normal form of the predicate $P$ (abbreviated as CDNF the predicate). The entry on the right-hand side of (40) means that a logical summation is carried out over all sets of objects $\left(a_{1}, a_{2}, \ldots, a_{n}\right)$, which is part of the relations $P$, corresponding to the predicate $P$.

Cartesian product $A_{1} \times A_{2} \times \ldots \times A_{n}$ of the sets $A_{1} \times A_{2} \times \ldots \times A_{n} \subseteq U$ corresponds the predicate $A_{1} \times A_{2} \times \ldots \times A_{n}$, values of which are determined by the formula

$$
\begin{gathered}
\left(A_{1} \times A_{2} \times \ldots \times A_{n}\right)\left(x_{1}, x_{2}, \ldots, x_{n}\right)= \\
=A_{1}\left(x_{1}\right) A_{2}\left(x_{2}\right) \ldots A_{n}\left(x_{n}\right) .
\end{gathered}
$$

Here $A_{i}$ - the predicate, corresponding to the set $A_{i} \quad i=\overline{1, n}$, standing at $i$ - place in a Cartesian product $A=A_{1} \times A_{2} \times \ldots \times A_{i} \times \ldots \times A_{n}$. Its values are sought by the formula

$$
A_{i}\left(x_{i}\right)=\underset{a \in A_{i}}{\vee} x_{i}^{a}
$$

If the set $A_{i}$ is final $\left(A_{i}=\left\{a_{1}, a_{2}, \ldots, a_{k}\right\}\right)$, Then the values of the corresponding predicate are determined by the formula

$$
A_{i}\left(x_{i}\right)=x_{i}^{a_{1}} \vee x_{i}^{a_{2}} \vee \ldots \vee x_{i}^{a_{k}} .
$$

The expression of the sets $A_{i}$ of formulas (41) and (42) reveals the following important fact: it turns out that predicate $A_{i}\left(x_{i}\right)$, corresponding to the set $A_{i}$, Describes not only this the set itself, but also its place in the Cartesian product $A=A_{1} \times A_{2} \times \ldots \times A_{i} \times \ldots \times A_{n}$. This place is represented by a variable $x_{i}$. So the expression of the set $A_{i}$ the predicate $A_{i}\left(x_{i}\right)=x_{i}^{a_{1}} \vee x_{i}^{a_{2}} \vee \ldots \vee x_{i}^{a_{k}}$ characterizes the set more fully than the record $A_{i}=\left\{a_{1}, a_{2}, \ldots, a_{k}\right\}$.

Let's consider, for example the Cartesian product $A=M \times M$, where $M=\{a, b\}$. To the set $M$, standing in first place in $A$, according to (42) there corresponds a predicate $M\left(x_{1}\right)=x_{1}^{a} \vee x_{1}^{b}$. To the set 
$M$, standing in second place in $A$ and having the same number and the same composition of elements, there corresponds another predicate: $M\left(x_{2}\right)=x_{2}^{a} \vee x_{2}^{b}$.

Let $P$ - the relation, defined for the Cartesian product $\quad A=A_{1} \times A_{2} \times \ldots \times A_{n}, \quad$ where $A_{1} \times A_{2} \times \ldots \times A_{n} \in U$. The relation $P$ can be formally expressed by any predicate $P$, defined for $U^{n}$, which satisfies the condition: $P\left(x_{1}, x_{2}, \ldots, x_{n}\right)=1$, if $\left(x_{1}, x_{2}, \ldots, x_{n}\right) \in P ; \quad P\left(x_{1}, x_{2}, \ldots, x_{n}\right)=0, \quad$ if $\left(x_{1}, x_{2}, \ldots, x_{n}\right) \in A_{1} \times A_{2} \times \ldots \times A_{n} \mid P$. Outside the region $A_{1} \times A_{2} \times \ldots \times A_{n}$ of the value of the predicate $P$ an be chosen arbitrarily. The fact of setting the relations $P$ on a Cartesian product $A$ formally expressed by a system of equations

$$
A_{1}\left(x_{1}\right)=1, A_{2}\left(x_{2}\right)=1, \ldots, A_{n}\left(x_{n}\right)=1,
$$

bounding values of variables $x_{1}, x_{2}, \ldots, x_{n}$ of the sets $A_{1}, A_{2}, \ldots, A_{n}$.

Trying to describe in the language of predicate algebra the relation of equality $D$, defined for $U$, we find that there is more than one predicate corresponding to this relation $D$, but a whole family of predicates $D\left(x_{i}, x_{j}\right) \quad(i \neq j, \quad i, j=\overline{1, n})$, which depend on all possible pairs of arguments.

Thus, we are forced to distinguish between the relations of equality, depending on where in $n$ component set are the elements associated with this relation of equality.

To the equality $D$, connecting the elements in $n$ component set on $i-\mathrm{M}$ and $j-\mathrm{M}$ places, there corresponds a predicate $D$, whose values are determined by the formula:

$$
D\left(x_{i}, x_{j}\right)=\underset{a \in U}{\vee} x_{i}^{a} x_{j}^{a} .
$$

If the universe is finite $\left(D=\left\{a_{1}, a_{2}, \ldots, a_{k}\right\}\right)$, then formula (43) can be written in the form

$$
D\left(x_{i}, x_{j}\right)=x_{i}^{a_{1}} x_{j}^{a_{1}} \vee x_{i}^{a_{2}} x_{j}^{a_{2}} \vee \ldots \vee x_{i}^{a_{k}} x_{j}^{a_{k}} .
$$

Let's call the set the same if the corresponding predicates depend on the same variable. Let the same type of the set $A$ and $B$ correspond to predicates $A\left(x_{i}\right)$ and $B\left(x_{i}\right) \quad(i=\overline{1, n})$. Then the union $A \cup B$ these sets correspond to the predicate

$$
(A \cup B)\left(x_{i}\right)=A\left(x_{i}\right) \vee B\left(x_{i}\right) .
$$

To the intersection $A \cap B$ of the sets $A$ and $B$ corresponds the predicate

$$
(A \cap B)\left(x_{i}\right)=A\left(x_{i}\right) \wedge B\left(x_{i}\right) .
$$

To the addition $\tilde{A}$ of the set $A$ corresponds to the predicate

$$
(\tilde{A})\left(x_{i}\right)=\overline{A\left(x_{i}\right)} .
$$

It is seen that the union, intersection and addition of predicates coincide, respectively, with their disjunction, conjunctions and negations, (29) - (31). In the same way, the disjunction, conjunction and negation of predicates corresponding to these theses correspond to the unification, intersection and addition of the relations. It can be shown that at such a definition of operations $\cup, \cap$ and $\sim$ for the sets and of the relations they will satisfy all the basic identities of Boolean algebra.

We note that an empty set $\varnothing$ corresponds to the predicate

$$
\varnothing\left(x_{i}\right)=0
$$

for every $x_{i} \in U$. The universal set $U$ corresponds to the predicate

$$
U\left(x_{i}\right)=1
$$

for every $x_{i} \in U$. Similarly, to empty and complete relations correspond predicates identically false and identically true.

\section{Conclusions}

The predicates of different orders correspond to concepts of a different level of abstraction.

The solution of algebra of finite predicates (AFP) equations can be interpreted as a creative activity of a human.

Due to the presence of such a broad meaningful interpretation, even the purely mathematical development of the AFP allows at the same time to advance the development of the theory of intelligence.

The minimization, decomposition, solution of equations, identical transformation of formulas are the important tasks of the theory of intelligence. In this area there are obtained already significant results.

Thus, the AFP formulas can be directly interpreted as phrases of the natural language; the predicates denoted by formulas - as human thoughts; operations on the predicates - as human intellectual activity. The AFP equations are interpreted as the laws of thought. The minimization of formulas is directly connected with the laconism of speech.

The decomposition of formulas corresponds to the dismemberment of the text into separate sentences in the process of speech.

\section{REFERENCES}

1. Khudhair, Abed Thamer (2017), "The formal basis of the intelligence theory mathematical apparatus", Suchasni informacijni sistemi [Advanced Information Systems], Vol. 1, No 1, pp. 38-43.

2. Bondarenko, M.F., Shabanov-Kushnarenko, Yu.P. and Shabanov-Kushnarenko, S.Yu. (2011), "Modeli komparatornoy identifikatsii $\mathrm{v}$ vide semeystv integral'nykh odno- i dvukhparametricheskikh operatorov" [Models of comparative identification in the form of families of integral one- and two-parameter operators], Bionika intellekta [Intelligence Bionics], No 2. pp. 86-97. 
3. Shabanov-Kushnarenko, S.Yu. (2015), Comparatornaya identifikaciya processov mnogomernoy kolichestvennoy ocenki [Multidimensional quantitative estimation processes comparative identification] Saarbrucken, Deutschland: Palmarium Academic Publishing, 217 p.

4. Bondarenko, M.F. and Shabanov-Kushnarenko, Yu.P. (2007), Teoriya intellekta [Intelligence theory], SMIT, Kharkiv, 576 p.

5. Shabanov-Kushnarenko, S.Yu., Kalinichenko, O.V. and Kovalenko, A.I. and Shmatko, A.A. (2015), "O formalizacii znaniy na baze akgebry konechnyh predikatov" [About the finite predicates algebra knowledge based formalization] // Zbirnyk Harkivskogo nacionalnogo universytetu Povitryanyh Syl [Collected papers of the Air Force Kharkov National University] [Bulletin of the Ukraine HAC], No. 3 (44), pp. 70-73.

6. Kalinichenko, O.V., Shabanov-Kushnarenko, S.Yu. and Yarmak, A.V. (2015), “O predikatnyh modelyah neyavnyh znaniy v zadachah analiza informacionyh processov" [On implicit knowledge predicate models in problems of information processes analysis] // Zbirnyk Harkivskogo nacionalnogo universytetu Povitryanyh Syl [Collected papers of the Air Force Kharkov National University] [Bulletin of the Ukraine HAC], No. 2 (43). pp. 46-49.

7. Shabanov-Kushnarenko, S.Yu., Khudhair Abed Thamer and Leshchynska, I.O. (2013), "Razrabotka predikatnyh modeley logicheskih svyazey ponyatiy" [Development of logical connections concepts predicate models], Zbirnyk Harkivskogo nacionalnogo universytetu Povitryanyh Syl [Collected papers of the Air Force Kharkov National University] [Bulletin of the Ukraine HAC], No. 4 (37). pp. 72-75.

8. Sutton, R.S. and Barto, A.G. (2016), Reinforcement Learning: An Introduction. Second edition, in progress. A Bradford Book. The MIT Press. 455 p.

9. Red'ko, V.G. (2011), Evolyuciya, neyronnye seti, intellect. Modeli i koncepcii evolyucionnoy kibernetiki [Evolution, neural networks, intelligence. Models and concepts of evolutionary cybernetics], Seriya: Sinergetika: ot proshlogo k buduschemu [Series: Synergetics: from past to future], Libercom, Moscow, $224 \mathrm{p}$.

10. Russell, S. and Norvig, P. (2009), Artificial Intelligence: A Modern Approach, Prentice Hall, (3 edition), 1152 p.

11. Flreani, D. and Mattiussi, C. Bio-Inspired Artificial Intelligence: Theories, Methods, and Technologies (Intelligent Robotics and Autonomous Agents series), The MIT Press, 2008, $658 \mathrm{p}$.

12. Petrunin, Yu.Yu., Ryazanov, M.A. and Savel'ev, A.V. (2010), Filosofiya iskusstvennogo intellekta v koncepciyah neyronauk [Philosophy of artificial intelligence in the neuroscience concepts], Max Press, Moscow, 78 p.

Надійшла (received) 31.05.2017

Прийнята до друку (accepted for publication) 18.10.2017

\section{Відношення і операції над предикатами в теорії інтелекту}

Кудхаір Абед Тамер

Мета. Метою статті є розробка формальної методики теорії інтелекту, а саме розробка моделі і аксіоматики на мові алгебри кінцевих предикатів. Пропонується ввести систему операцій за відносинами для побудови алгебри відносин. Методи. У статті використані методи алгебри кінцевих предикатів, булева алгебра і аксіоматичний метод. Результати. У статті був розвинений математичний апарат теорії інтелекту. Розроблено моделі та аксіоматику відносин на мові алгебри кінцевих предикатів, введені операції над такими відносинами, як ін'єкція, еквівалентність, сюр'єкція, квазіпорядок, частковий порядок, циркуляція і добуток відносини. Побудована алгебра відносин. Аксіоматично призначається система операцій над предикатами в алгебрі скінченних предикатів, а саме: булеве заперечення, диз'юнкція, кон'юнкція, імплікація, еквівалентність. Вводяться основні предикати (предикати розпізнавання об'єктів). Висновки. Предикати різних порядків відповідають поняттям іншого рівня абстракції. Рішення рівнянь алгебри кінцевих предикатів можна інтерпретувати як творчу діяльність людини. Через наявність такої широкої і змістовної інтерпретації навіть чисто математичний розвиток алгебри кінцевих предикатів дозволяє в той же час стимулювати розвиток теорії інтелекту. Мінімізація, декомпозиція, рішення рівнянь, тотожне перетворення формул $\epsilon$ важливими завданнями теорії інтелекту.

Ключов і слов а : теорія інтелекту; алгебра скінченних предикатів; компараторна ідентифікація.

\section{Отношения и операции над предикатами в теории интеллекта}

\section{Кудхаир Абед Тамер}

Цель. Целью статьи является разработка формальной методики теории интеллекта, а именно разработка модели и аксиоматики на языке алгебры конечных предикатов. Предлагается ввести систему операций по отношениям для построения алгебры отношений. Методы. В статье использованы методы алгебры конечных предикатов, булева алгебра и аксиоматический метод. Результаты. В статье получил дальнейшее развитие математический аппарат теории интеллекта. Разработаны модели и аксиоматика отношений на языке алгебры конечных предикатов, введены операции над такими отношениями, как инъекция, эквивалентность, сюръекция, квазипорядок, частичный порядок, циркуляция и произведение отношения. Построена алгебра отношений. Аксиоматически назначается система операций над предикатами в алгебре конечных предикатов, а именно: булево отрицание, дизъюнкция, конъюнкция, импликация, эквивалентность. Вводятся основные предикаты (предикаты распознавания объектов). Выводы. Предикаты разных порядков соответствуют понятиям другого уровня абстракции. Решение уравнений алгебры конечных предикатов можно интерпретировать как творческую деятельность человека. Из-за наличия такой широкой и содержательной интерпретации даже чисто математическое развитие алгебры конечных предикатов позволяет в то же время стимулировать развитие теории интеллекта. Минимизация, декомпозиция, решение уравнений, тождественное преобразование формул являются важными задачами теории интеллекта.

Ключев ые слов а: теория интеллекта; алгебра конечных предикатов; компараторная идентификация. 